\title{
Dynamic Assessment of Nature Based Solutions Through Urban Level LCA
}

\author{
Duygu Başoğlu, Emre Yöntem, Seda Yöntem, Beril Şenyurt \\ and Özge Yılmaz
}

\begin{abstract}
Planning Nature Based Solutions (NBS) to address urban challenges requires an approach that embeds the multiple dimensions of NBS to effectively portray their use and impact. Life Cycle Assessment (LCA) provides a comprehensive assessment methodology in this regard. This paper discusses the environmental assessment of NBS via LCA using urban metabolism as an overarching approach to model the urban ecosystem. Performing a dynamic assessment with time series data is suggested as a way of identifying hotspots of the indicators studied within a determined time frame, allowing the assessor to observe and mitigate extremities and make informed decisions on desired temporal patterns. Dynamic assessment is supported by two simulation methodologies: Building Information Modelling for the built environment and Agent Based Modelling for social behavioural patterns.
\end{abstract}

\section{Introduction}

Cities consume $75 \%$ of the world's resources, generate around $75 \%$ of greenhouse gas emissions globally, and are responsible for $60-80 \%$ of energy consumption around the world [5]. Poverty and urban decay are rising problems. Yet urbanization is also inevitable as a necessity to accommodate the growing world population in limited land, and as hubs that provide economic, social and environmental potential. Over half of the world's population lives in cities, with more than $20 \%$ in cities with a population over 1,000,000, while cities occupy less than $2 \%$ of the surface area of the earth. Urban areas generate around $80 \%$ of the global economic output [1-5]. This is made possible by the critical density provided by cities as arenas of agglomeration economies and sharing [6].

\footnotetext{
D. Bașoğlu $(\bowtie) \cdot$ E. Yöntem · S. Yöntem · B. Șenyurt · Ö. Yı1maz

Ekodenge Consultancy Engineering Architecture Inc., 06800 Ankara, Turkey

e-mail: duygu.basoglu@ekodenge.com

(C) The Author(s) 2018

E. Benetto et al. (eds.), Designing Sustainable Technologies,

Products and Policies, https://doi.org/10.1007/978-3-319-66981-6_32
} 
Rapid urbanization following the industrial revolution has shaped cities as consumers of resources, pictured in a frame of antagonism with nature. However, UN HABITAT points that today cities stand out as land use efficient accommodations for large populations: they actually need four times less land and ten times less local road than rural areas [1]. Yet this also indicates a concentrated demand for various resources, which may exceed local supply and require consumption of commodities produced all around the world and transported in long distances. Improving the quality, resilience and resource efficiency of urban space is the key to maintain them as sustainable alternatives to sprawl which consumes agricultural land and the wilderness.

Many opportunities exist for cities to tackle the challenge of sustainability. Cities need to follow the example of natural ecosystems and their metabolisms to be reformulated as balanced, circular, and to whatever possible extent, self-sustaining systems. Whether man-made or based on natural ecosystems, different alternatives should be evaluated and prioritized with regards to their potential to achieve sustainability goals by means of a sound assessment methodology. A way of designing natural elements as a tool for sustainability in cities is called Nature Based Solutions (NBS). NBS are means of bringing nature back into cities for the provision of ecosystem services and related environmental, social and economic benefits as a tool for achieving urban sustainability.

This paper studies urban scale life cycle assessment (LCA) as a comprehensive assessment methodology and its application to assessing NBS. Considering that achieving grounded results through LCA is highly dependent on data, the main challenge is modelling urban space efficiently to portray the network of resources, environmental impact, and the behavioural impact on citizens. Opportunities brought by the capability to generate and process more data lead to discussions regarding adding dynamic elements to LCA, which is inherently static. The urban metabolism approach seeks to model the city as a system of flows that creates inputs and outputs, while generating results from the interactions of flows, as in the metabolism analogy. Further discussions focus dynamic modelling to comprehend the changing trends of flows, and on integrating time series data for this. The concept of agent-based modelling (ABM) is discussed for the social layer of the urban area and behavioural changes. The use of building information modelling (BIM) is finally discussed to provide time series data for the built environment, enabling a more precise estimation of flows related to energy, consumption and pollution.

\section{Nature Based Solutions}

NBS are defined as interventions inspired or supported by nature and suit many of the dynamic challenges cities face as they respond to multiple purposes. They are often resilient, adaptable, resource efficient, locally adjustable and optimized [7-9]. The term "Nature Based Solutions" entered scientific literature in the agricultural 
context and migrated into design as the use of nature as a component or a subject of study for solutions inspired by it. Following their use in ecosystem-based adaptation for reducing climate-based risks, the use of NBS for urban planning has been referred to by the UN Secretary General in 2013 [10] and is currently on the research agenda of the EU [9]. They respond to the complex problems of cities with multiple purpose solutions, and enrich the urban environment by re-naturing.

To illustrate the applicability of NBS across scales for multiple challenges, two examples can be used. The Cheong Gye Cheon Restoration Project in Korea is an example of large scale urban generation by NBS, where an overpass was removed and the exposed river channel was landscaped. This intervention generated benefits to the whole urban area, including those related to biodiversity, economic growth, tourism, and urban revitalisation while mitigating urban heat island by a $3.6^{\circ} \mathrm{C}$ thermal relief measured on July 27 th [11].

A smaller scale example of NBS could be the green façade implemented on the Vienna Magistrate MA48 Building (Fig. 1), which has provided aesthetic, biodiversity and thermal advantages for its surroundings and benefited the building with up to $50 \%$ reduction in heat loss in winter and a cooling effect in summer that is equivalent to 45-3000 W air conditioning units [12]. Both examples have targeted multiple issues related to different scales in changing conditions. Even when an NBS is selected for a focused motive, such as mitigating the surface temperature of a building, side benefits occur as a result of the complex and multi-layered aspect of

Fig. 1 "Climate façade" on the MA48 building, Vienna

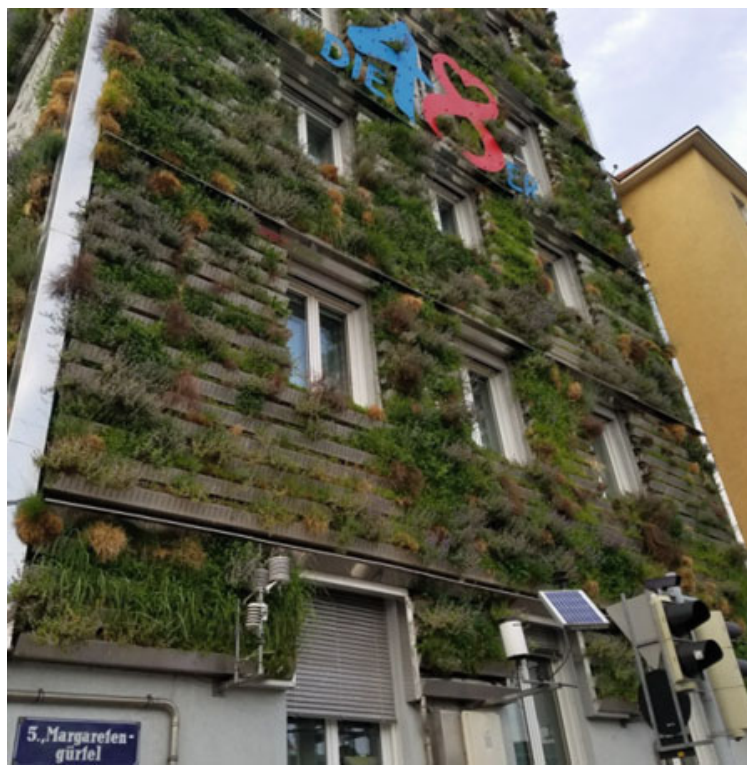


natural elements. This portrays the need for assessment and decision support tools that can model complex relations and integrate the multiple benefits of NBS to effectively support their use in addressing urban challenges.

\section{Urban Scale LCA for the Evaluation of NBS}

\subsection{Life Cycle Assessment (LCA) and Urban Metabolism (UM)}

As stated earlier, urban activities are among the major sources of sustainability issues, in particular global climate change; yet, they are also highly vulnerable to the effects of such issues. Through utilization of various assessment tools ranging from indicators to complex models, urban sustainability assessment provides insight to the current state of the environment, causes of environmental impacts, hotspots among these causes, which ultimately lead to performance evaluation of initiatives and policies for sustainable urban development [13]. Consequently, it is imperative to conduct sustainability assessment for monitoring and measuring the past or current environmental pressures, states, or impacts of urban areas. Urban assessments help cities to identify main bottlenecks regarding resilience, vulnerability to climate change, food, water and energy security issues and develop sound strategies or policies to tackle them.

LCA is a holistic methodology capable of revealing a broad range of environmental impacts in a systematic way and has been widely used for urban sustainability assessment [17]. Through LCA, it is possible to go beyond inventorying direct consumption and emissions, and consider transboundary or cross media effects embedded in urban flows and stocks. Of course, this is only possible by means of reflecting the complexity of urban systems, which are comprised of layers of sub-systems in LCA system models.

NBS are among the strategies that can benefit from such a holistic assessment due to their utility under themes including greenhouse gas emissions, biodiversity, water, urban food, air and health [14]. Moreover, LCA is also suitable to address the multi layered nature of NBS as it covers various environmental mechanisms revealing information on different impacts at different scales that apply to mid-point and end-point results.

To be able to reach the desired level of representation of complex urban systems, the conceptual models developed during system boundary definition stage of LCA can benefit from the urban metabolism (UM) approach. This is a good foundation for identifying the relevant urban flows within the system boundary and their interactions. The UM approach is based on an analogy for the resource consumption and waste generation of cities, resembling the requirement for nutrient 
intake, energy demand, consequent growth and production of metabolic wastes of a living organism [17]. It is defined as "a broad range of quantitative methods that attempt to conceptualize urban areas as organisms, requiring goods and energy to maintain functionality and support growth, while emitting waste as a by-product" [15]. Due to the complexity of urban systems, they can be considered to be more similar to ecosystems encompassing a group of multiple individuals, located within their environment, interacting among themselves and in a place [16] rather than single organisms. UM supports LCA by allowing the practitioner to analyse interlinked urban sub-systems from a holistic point of view.

UM of cities can be studied alternatively by different approaches, one of which is Odum's emergy approach, which describes the accounting of UM flows in terms of (solar) energy equivalents, thus translating city's flows of material, nutrient, services and wastes in one common unit of measurement [17]. Beyond conceptual system model definition, UM also supports LCA through the identification of urban metabolic flows. This identification entails two basic types of cycles within the cities; the operating cycle and investment cycle. Operating cycle is comprised of the continuous flows within the system boundary, whereas the investment cycle contains the flows that turn into stock, which has a non-continuous and accumulative character [18]. By analysing these different types of urban cycles, UM approach allows us to monitor the temporal changes within cities and supports dynamic urban LCA studies. This can enable the assessor to identify hotspots of the indicator studied within the determined period of time, allowing to identify and mitigate extremities, make decisions based on desired performance patterns over time and optimize the life span of the study.

Although LCA is a methodologically well-established assessment with applicable ISO standards 14040 and 14044, data availability and quality can become important bottlenecks for an LCA study. This limitation imposed can be more pronounced for complex urban systems, where without proper inclusion of all relevant data on flows, benefits of sustainability strategies with multiple target improvements such as NBS cannot be revealed. Furthermore, the evaluation of resilience issues and decisions on adaptation and mitigation strategies for cities is highly dependent not only on the current status of the environment but also on future trends. Finally, the environmental performance of cities, their vulnerability to extreme events and the availability of resources to all citizens in fairness has direct implications on social structure. Therefore, sustainability assessment needs to consider problems of urban planning interlinked to its scope and cover social aspects.

The question here is how to amend and support environmental sustainability assessment through LCA with additional tools. Opportunities in achieving data for such a tool lie in supplementing LCA with BIM and dynamic social assessment. 


\subsection{A Data Centric Approach for Urban Level Complex Assessments}

Just like the accuracy and precision of an LCA study being highly dependent on data quality, urban metabolism models also rely on obtaining and generating realistic data as pointed earlier. This leads the practitioner to a data centric approach for urban level complex assessments which can be based on a trend that builds upon business intelligence towards a smart city approach operating via large quantities of complex data.

In their comprehensive literature review study, Beloin-Saint-Pierre et al. have categorised the urban metabolism modelling strategies into Black Box, Grey Box and Network approaches. Starting from the basic simplified input and output data of the Black Box Approach, the Grey-Box Approach studies further level of inner flows and the Network Approach defines the links on all inner components of the studied system. The main drawback of the Network Approach is identified to be the challenging implementation of analyses due to the big amount of data. This fact can be easily accepted as a reason of complexity yet still being the solution towards answering multi-dimensional analyses that can be very beneficial for urban level decision making [19].

The handling of such complex data can be studied through the business intelligence approach, which has roots in the database management field and benefits from various data collection, extraction, and analysis technologies [20]. Development in data analytics technologies has led to the Internet as a platform and eventually cloud-based data hosting and analyses capabilities. Business intelligence has evolved because the amount of data generated through the internet and smart devices has grown exponentially altering how organizations and individuals use information [21]. Current technological advancements in the data analytics fields and accessibility of complex data analytics algorithms within the cloud services offer a promising and reliable platform to realize data centric assessments.

The age of "big data" has also led to the transparency, accessibility and interoperability of data repositories. EU has initiated and mobilised the INSPIRE directive [22], identifying standards for data sets, and their distributed services. Urban level data management and referencing standards have also been emerging. One of these standards is the BSI Guide to establishing a model for data interoperability, which aims to look beyond the current use of data to facilitate city services, and encourage decision-makers to explore the reuse of data as a resource to innovate the future direction of systems and services. This standard identifies four key types of insight to be required when sharing data in a city; operational insight examining the characteristics of urban elements, critical insight for real time monitoring, analytical insight for exploring the data ecosystem to determine patterns, and strategic insight for examining outcomes related to strategic objectives [23]. 
Open data and data sharing in cities regarding various urban systems from transportation to communication make various multi-dimensional and interrelated urban level assessments possible. Relying on this background, supported with the enhanced analytical assessment capabilities decision makers can be served with complex interdependent analyses such as LCA, social and economic analyses.

This data centric trend in urban analysis makes the generation of data central to further studies. Big data capabilities bring forth an opportunity as they can now integrate detailed forecasts such as dynamic assessment into assessment procedures and details down to building level can be considered for urban analyses. This paper will proceed to explore some of these opportunities.

\subsection{Dynamic Social Assessment}

As pointed earlier, the significance of cities comes mainly from the fact that they accommodate most of the world's population, and even more, provide a sharing and meeting ground for their activities. Social wellbeing is thus a major goal of urban space. As citizens and related actors which can be studied as agents are continuously adapting their behaviours, it is crucial for the decision maker to understand the interaction of citizens with the studied urban system.

UM provides a detailed view on the physical space of the city, even incorporating inter-boundary relations as flows and allowing temporal results. Yet the social layer is different than any other flow: its agents, individual people, are more complex. The question is whether it is possible to include them in a model of UM.

A research held by UCL classifies debates on UM and reflects on the social implications of urban metabolism by pointing that even though urban space is modelled in units of spaces, materials and physical systems, social consequences occur and this layer is also a part of the metabolism [24]. Studies in terms of class and inequalities in relation to infrastructure networks define the term "social metabolism" proposed by Martinez-Alier as "a manner in which human societies organize their growing exchanges of energy and materials with the environment" $[24,25]$. These studies point at UM as a driver for major social movements and changes descriptively. However, an approach such as ABM that quantifies changes in behaviour over time and in relation to flows and trends of the UM is needed to complement the dynamic assessment approach this paper discusses.

$\mathrm{ABM}$ is a computational tool that is capable of examining social systems with the perspective of a complex adaptive system. It studies how macro effects emerge from micro scale behavioural patterns among heterogeneous social agents, which are evolving, autonomous and interacting [26]. 
ABM simulations handle the mathematically abstracted environment and the interactions with the involved entities in time series iterations, where the frequencies and time span can be selected to best represent the studied system. This can be citizens in an urban system, aligned with the time patterns of flows. This approach can directly benefit from data sources, where the related parameters effecting the agents' behaviours are made available in the identified resolution in terms of iteration frequencies and quality. To provide the required background for the simulations at the urban ecosystem, multidimensional data needs to be utilised. This includes the spatial urban data in the form of GIS, BIM and CIM (City Information Model) models, material and energy flow data in the form of UM approach, weather and climate related time series data.

\subsection{Developing an Integrated Assessment Platform for NBS}

The assessment method proposed for Nature4Cities, a flagship HORIZON2020 project on NBS, aims to integrate multiple tools that incorporate modelling abilities at different scales and techniques such as remote sensing for a platform that covers economic, social and environmental aspects of NBS. The environmental assessment module is planned to handle the relation between the UM and social well-being through ABM along with LCA for the assessment of environmental impacts. The project aspires for a holistic assessment of NBS, making the discussed data needs critical. This approach shall look into the relations of urban flows' distribution, intensity, services and impacts with the behaviour of citizens as agents. Dynamic assessment covers the changing nature of this interaction: supply of flows influences the decisions and behaviours of the population, resulting in changes in the settlement pattern, creating or reducing demand in flows over time.

The EPESUS City platform will be part of the technologies that contribute to the integrated assessment platform of Nature4Cities along with other novel technologies. It is an ICT tool that performs life cycle assessment at the urban scale in a time series approach [30]. This enables the assessor to identify hotspots of the indicator studied within the determined period of time, allowing to identify and mitigate extremities, make decisions based on desired performance patterns over time and optimize the life span of the study.

\subsection{Integrating BIM and New Opportunities}

Integrating BIM to urban assessment suggests new opportunities in improving the precision of data sources for LCA and the scalability of assessment at different 
levels. BIM is basically digitally representing a building or built object, attributing physical and functional properties gathered from all contributors to the design and implementation. A major benefit of using BIM is enabling collaboration in-between different stakeholders through the interoperable, shared representation of the object $[27,28]$ and this applies to the different tools and approaches proposed for assessment here. For NBS, this perspective of object level modelling is promising as many solutions offer different impacts at object level, such as regulating functions related to thermal comfort, while contributing to the urban environment's cumulative natural assets, such as the carbon storage of a city.

EPESUS software has been using BIM to generate detailed data for Sustainable Energy and Carbon Action Plans (SECAP) for local governments [30]. DesignBuilder software is used as a building energy modelling interface for Energy + to generate time series energy consumption data for the building models. Building types are determined based on available data and surveys held in the subject area of the SECAP. These types are then attributed to building masses drawn on a GIS interface of the city and their building energy model data is extrapolated in EPESUS. Results are calibrated to achieve the closest alignment with real bill data and spatial distribution based on neighbourhood characteristics. Upon obtaining a baseline, scenarios are studied based on proposed interventions such as envelope specifications and heating and cooling systems.

Such use of BIM for allocation to GIS units has been referred to as a City Information Model (CIM): incorporating object models that generate data to decision support tools using GIS [29]. What EPESUS does (Fig. 2) is using BIM and generating assumptions, aligning them with real data and achieving scenarios on a GIS in this regard. EPESUS is currently capable of modelling energy consumption, carbon emissions and life cycle impact, also delivering hotspots in the impact area. EPESUS can also visualize impacts like pollution as heat-maps.

These capabilities provide a good base to integrate NBS into an assessment method that imports time series data and delivers a dynamic assessment, with an ability to use BIM to consider micro scale impacts. Having detailed information at object level allows EPESUS to display heat-maps over a GIS interface to visualize local conditions. NBS can be part of the BIM stage of this assessment method. Such an LCA tool with GIS capabilities is functional to see some of the most desired effects of NBS including:

- Urban heat island mitigation in areas of reflective surfaces and dense population,

- Pollution control based on heat-maps resulting from energy systems and density,

- Areas' desirability for urban agents and behavioural impact,

- Other local ecosystem services such as biodiversity support. 

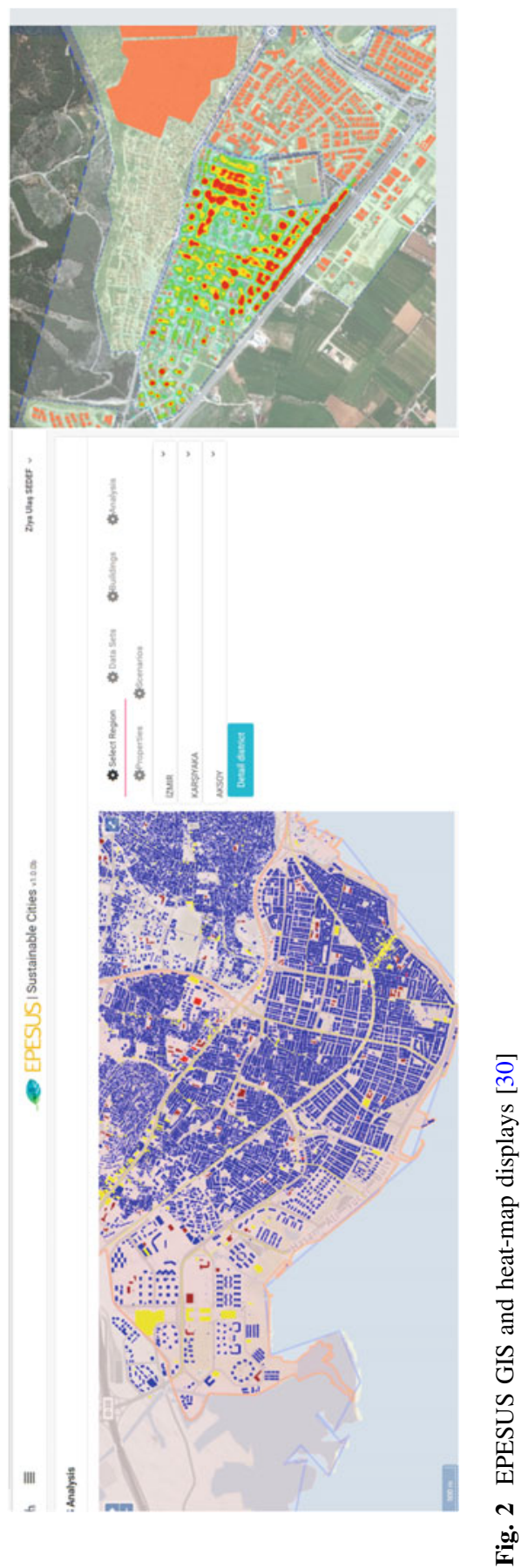


\section{Conclusions}

The Environmental Assessment of NBS Understanding the environmental impacts of NBS requires different levels of results: urban level, object and area level, and the interactions and temporal patterns for different scales. While LCA is a wellestablished environmental assessment method guided by ISO standards 14040 and 14044 , the results it generates are only as good as the data in the hands of the practitioner. Therefore, a major challenge in rendering the multi benefit and interlinked nature of NBS is to model the urban system efficiently. This requires collecting reliable data for this model, and estimating temporal patterns via suitable modelling approaches.

The UM approach illustrated in Fig. 3 is viable for understanding the links between flows influenced by NBS interventions. However, for a detailed understanding of these flows, additional parameters of the urban system model are necessary. Today, ABM provides opportunities in calculating dynamic results regarding the impacts of NBS in behavioural patterns to cover social aspects that are integral to urban assessment. In addition, established BIM tools are capable of providing time series data, which is a promising area for enhancing dynamic urban level assessment. Together, these approaches provide a state-of-the-art solution to obtaining detailed dynamic data for an LCA study of NBS in urban assessments.

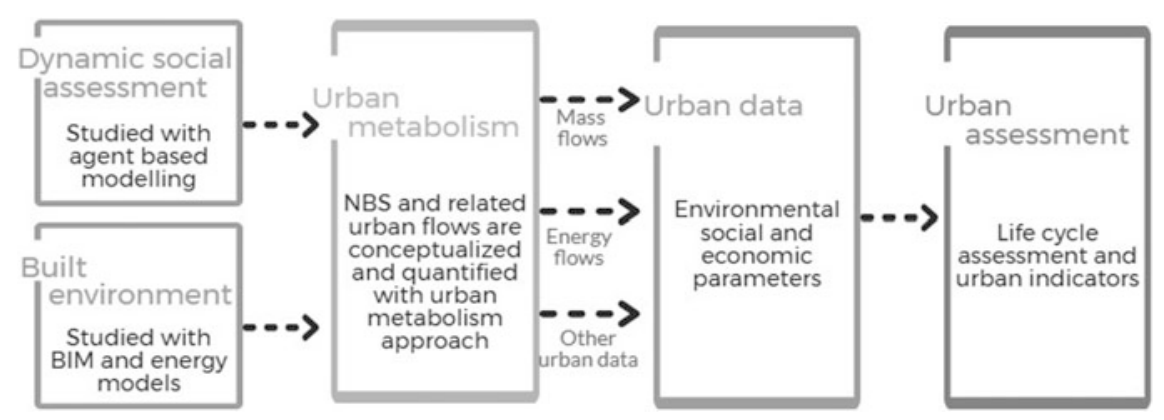

Fig. 3 Environmental assessment of NBS using the UM approach 
Acknowledgements Nature4Cities project has received funding from the European Union's Horizon 2020 research and innovation programme under grant agreement No. 730468.

\section{References}

1. UN, World Economic and Social Survey 2013. 2013.

2. UN Population Division, The World's Cities in 2016: Data Booklet., p. 29, 2016.

3. EC and UN-Habitat, The State of European Cities 2016. 2016.

4. UNDESA, World Urbanization Prospects. 2014.

5. BRE, Cities as systems: BRE solutions for urban environments, 2015.

6. Keivani R, A review of the main challenges to urban sustainability, Int. J. Urban Sustain. Dev., vol. 1, no. 1-2, pp. 5-16, 2010.

7. De Boissezon B, Smart and sustainable cities with nature-based solutions, no. September, pp. 1-15, 2015.

8. Yeroyanni M, Commission E, Innovation Renaturing cities with nature based solutions ENERO Workshop: Fostering future integration of Environment in European research \& innovation no. October, 2014.

9. European Commission, Towards an EU Research and Innovation policy agenda for Nature-Based Solutions \& Re-Naturing Cities. 2015.

10. Potschin M, Kretsch C, Haines-Young R, Furman E, Berry P, Baro F, Nature-based solutions, OpenNESS Synth. Pap., no. 18, pp. 1-5, 2014.

11. Lee I.K, Cheong Gye Cheon Restoration Project, in ICLEI, 2006.

12. Naumann S, Kaphengst T, McFarland K, Stadler J, Nature-based Approaches to Climate Change Mitigation and Adaption, pp. 1-27, 2014.

13. Yigitcanlar T, Dur F, Dizdaroglu D, Towards prosperous sustainable cities: A multiscalar urban sustainability assessment approach, Habitat Int., vol. 45, no. P1, pp. 36-46, 2015.

14. Xing X, Jones P, Donnison I, Characterisation of Nature-Based Solutions for the Built Environment, Sustainability, vol. 9, no. 1, Jan. 2017.

15. Goldstein G, Birkved M, Quitzau M.B, Hauschild M.Z, Quantification of urban metabolism through coupling with the life cycle assessment framework: concept development and case study, Environ. Res. Lett., vol. 8, p. 35024, 2013.

16. Chrysoulakis N, et al., Sustainable urban metabolism as a link between bio-physical sciences and urban planning: The BRIDGE project, Landsc. Urban Plan., vol. 112, no. 1, pp. 100-117, 2013.

17. Kennedy $\mathrm{C}$, Pincetl $\mathrm{S}$, Bunje $\mathrm{P}$, The study of urban metabolism and its applications to urban planning and design, Environ. Pollut., vol. 159, no. 8-9, pp. 1965-1973, 2011.

18. SUME, Urban Metabolism: Sustainable Urban Metabolism for Europe (SUME) Project website. [Online]. Available: http://www.sume.at/urban_metabolism. [Accessed: 01-June-2017].

19. Beloin-Saint-Pierre D, et al., A review of urban metabolism studies to identify key methodological choices for future harmonization and implementation, J. Clean. Prod., 2015.

20. Chaudhuri S, Dayal U, Narasayya V, An overview of business intelligence technology, Commun. ACM, vol. 54, no. 8, p. 88, 2011.

21. Larson D, Chang V, A review and future direction of agile, business intelligence, analytics and data science, Int. J. Inf. Manage., vol. 36, no. 5, pp. 700-710, 2016.

22. EC, INSPIRE Legislation, 2014. [Online]. Available: http://inspire.ec.europa.eu/index.cfm/ pageid/3. [Accessed: 01-Jul-2017].

23. BSI, BSI Standards Publication Smart city concept model - Guide to establishing a model for data interoperability, pp. 1-56, 2014.

24. Rapoport E, CastánBroto V, Allen A, Interdisciplinary Perspectives on Urban Metabolism, J. Ind. Ecology, 2011. 
25. Martinez-Alier J, Kallis G, Veuthey S, Walter M, Temper L, Social metabolism, ecological distribution conflicts, and valuation languages, Ecol. Econ., vol. 70, no. 2, pp. 153-158, 2010.

26. Holland J.H, Complex Adaptive Systems, Daedalus, vol. 121, no. 1, A New Era in Computation, pp. 17-30, 1992.

27. National Institute of Building Sciences (NIBS), Frequently Asked Questions About the National BIM Standard-United States, 2014. [Online]. Available: http://www.national bimstandard.org/faq.php\#faq1.

28. O'Donnell J.T, et al., Transforming BIM to BEM: Generation of Building Geometry for the NASA Ames Sustainability Base BIM, Bim, no. January, p. 26, 2013.

29. Gil J, Almeida J, Duarte J. P, The backbone of a City Information Model (CIM), 29th eCAADe Conf., no. Cim, pp. 143-151, 2011.

30. Ekodenge, EPESUS City. [Online]. Available: http://www.ekodenge.com/epesus/epesus-city/ [Accessed: 01-June-2017].

Open Access This chapter is licensed under the terms of the Creative Commons Attribution 4.0 International License (http://creativecommons.org/licenses/by/4.0/), which permits use, sharing, adaptation, distribution and reproduction in any medium or format, as long as you give appropriate credit to the original author(s) and the source, provide a link to the Creative Commons license and indicate if changes were made.

The images or other third party material in this chapter are included in the chapter's Creative Commons license, unless indicated otherwise in a credit line to the material. If material is not included in the chapter's Creative Commons license and your intended use is not permitted by statutory regulation or exceeds the permitted use, you will need to obtain permission directly from the copyright holder.

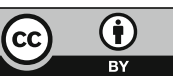

